\title{
Twenty-Four Hours of Mild Hypothermia in Unsedated Newborn Pigs Starting after a Severe Global Hypoxic-Ischemic Insult Is Not Neuroprotective
}

\author{
MARIANNE THORESEN, SAULIUS SATAS, ELSE MARIT LØBERG, ANDREW WHITELAW, \\ DOMINIQUE ACOLET, CARL LINDGREN, JULIET PENRICE, NICOLA ROBERTSON, \\ EGIL HAUG, AND PETTER ANDREAS STEEN \\ Departments of Experimental Medicine [M.T., S.S., A.W., P.A.S.], Pathology [E.M.L.], Paediatrics [C.L.], \\ and Anaesthesiology [P.A.S.], Ullevål Hospital, Oslo, Norway; Department of Endocrinology, Aker \\ University Hospital, Oslo, Norway [E.H.]; Division of Child Health, University of Bristol, United \\ Kingdom [M.T., S.S., A.W.]; Department of Pediatrics, Chelsea and Westminster Hospital, London, United \\ Kingdom [D.A., J.P.]; Department of Pediatrics, University College Hospital, London, United Kingdom \\ [J.P.]; and Department of Pediatrics, Imperial College, London, United Kingdom [N.R.]
}

\begin{tabular}{|c|c|}
\hline \multicolumn{2}{|c|}{ ABSTRACT } \\
\hline 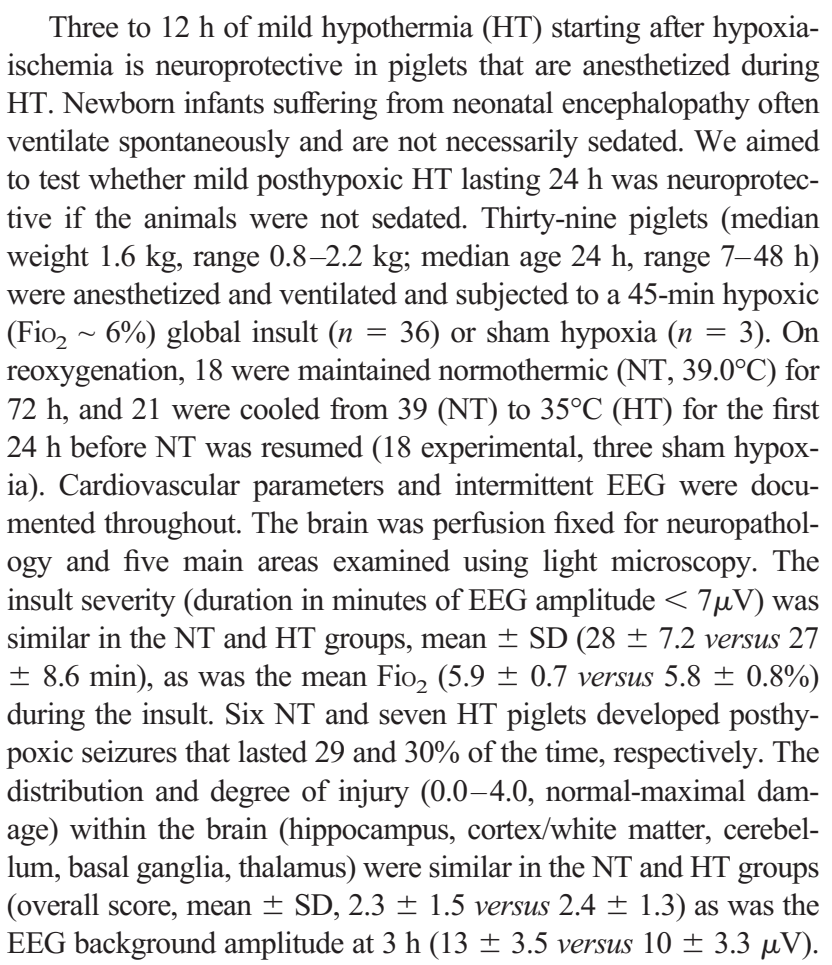 & 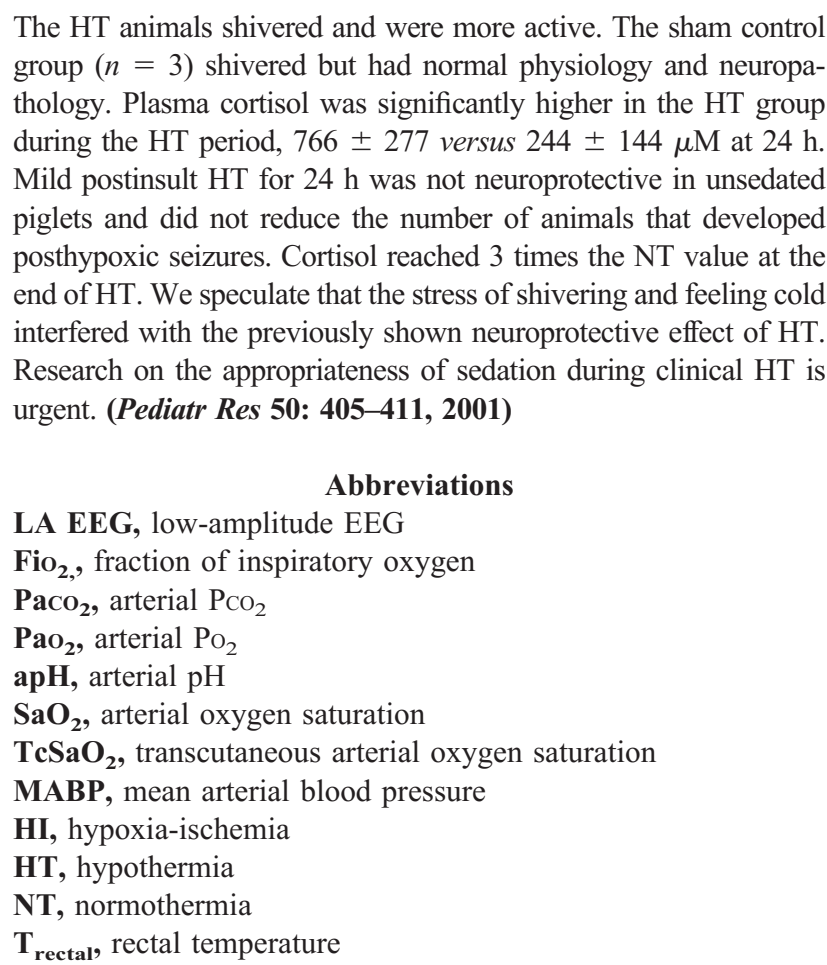 \\
\hline
\end{tabular}

Many studies on newborn animal models show that mild HT, which starts after an HI insult, is neuroprotective (1-5). The duration of HT in these studies varies from 3 to $72 \mathrm{~h}$,

Received November 7, 2000; accepted May 11, 2001

Correspondence: Dr Marianne Thoresen, M.D., St Michaels Hospital, Level D, Department of Child Health, University of Bristol, Southwell Street, BS2 8 EG, Bristol, United Kingdom; e-mail: marianne.thoresen@bris.ac.uk and the reduction in body temperature varies between 3.5 and $6^{\circ} \mathrm{C}$. Some studies, however, show only a minor beneficial effect (6), or the neuroprotection is temporary and not maintained (7).

Supported by grants from The Laerdal Foundation for Acute Medicine, The Norwegian Research Council, Ullevål University Hospital Research Forum, and The Medical Research Council, UK. 
Most models of neonatal HI involve surgery for cerebral vessel occlusion and differ from clinical asphyxia in that only the brain and not the rest of the body is subject to the insult. We have developed a noninvasive global hypoxia model using the newborn piglet that develops clinical signs, particularly seizures, EEG abnormalities, and neuropathologic changes similar to those seen in infants suffering from neonatal encephalopathy (8).

Unlike adults and children after brain trauma $(9,10)$, newborn human infants with neonatal encephalopathy are not routinely anesthetized. Depending on local practice, the infants may be sedated during mechanical ventilation and intensive care and may receive anticonvulsive treatment if they develop clinical seizures (11).

The aim of this study was to examine whether mild HT (a reduction in body temperature of $4^{\circ} \mathrm{C}$ ) for $24 \mathrm{~h}$ after global $\mathrm{HI}$ in newborn piglets reduces 1 ) the extent of neuropathologic damage at 72-h survival and/or 2) the occurrence of posthypoxic seizures.

\section{METHODS}

The present study was approved by the Norwegian Experimental Animal Board. Forty-four healthy Landrace newborn pigs of either sex were removed from the sow $<3 \mathrm{~h}$ before the experiment started. Their median age was $24 \mathrm{~h}$ (range 7-48 h), median weight $1600 \mathrm{~g}$ (range 820-2230 g), median litter size 10.5 (range 4-17), and the median number of still births per litter 0 (range $0-3$ ). During and after transport, the piglets were kept in a warm quiet environment to minimize stress. They were bottle-fed pig formula ad libitum on arrival.

Two piglets were used in pilot experiments to investigate whether pethidine $10 \mathrm{mg} / \mathrm{kg}$ i.v. reduced shivering during hypothermia $\left(\mathrm{T}_{\text {rectal }}, 35^{\circ} \mathrm{C}\right)(12)$. Visible shivering was only mildly reduced, whereas spontaneous respiration was suppressed, arterial $\mathrm{PCO}_{2}$ rose, and $\mathrm{SaO}_{2}$ fell. We, therefore, accepted spontaneous shivering in the cooled animals in our experimental design $(13,14)$ so as not to impair spontaneous breathing. Three piglets were used as sham controls for the examination of the effect of unsedated HT without hypoxia on brain pathology. The experimental group comprised 39 piglets of which three died and were replaced. One animal had a massive pulmonary hemorrhage as well as profuse bleeding during preparation, and another had a sudden cardiac arrest before the insult. A third pig ( $6 \mathrm{~h}$ into HT) had a cardiac arrest as a result of a drug error.

Details of the methods and monitoring used have been reported previously (8). Briefly, animals were $\mathrm{N}_{2} \mathrm{O}$ /halothane anesthetized, intubated, and ventilated with $66 \% \mathrm{~N}_{2} \mathrm{O}, 33$ to $34 \% \mathrm{O}_{2}$, and $0.6-0.8 \%$ halothane. During baseline conditions, the ventilation was adjusted to keep end-tidal $\mathrm{CO}_{2}$ at 5.0 to 6.0 $\mathrm{kPa}$ and $\mathrm{TcSaO}_{2}$ at 95 to $98 \%$. Deep rectal (at $6 \mathrm{~cm}$ ) temperature was kept stable and normal for pigs at $39^{\circ} \mathrm{C}$ (range $\left.38.4-39.5^{\circ} \mathrm{C}\right)(15)$ and used as core temperature (16).

The umbilical vein and artery were catheterized for fluid infusion, blood sampling, and continuous arterial blood pressure monitoring. Arterial blood gases, glucose, and samples for hematology and biochemistry were sampled twice before, twice during, and at 1, 3, 6, 12, 24, 30, 48, and $72 \mathrm{~h}$ after the 45-min hypoxic insult. Baseline observations lasted a minimum of $60 \mathrm{~min}$ of stable blood gases, blood pressure, blood glucose, and normal temperature.

Two-channel EEG was recorded from skin electrodes over each hemisphere with interelectrode distances of $3 \mathrm{~cm}$, the placement corresponding to F1-P3 and F2-P4. The raw EEG signal was continuously recorded on tape (Oxford Medilog 9000, Oxford Medical, Abingdon, UK) before, during, and for the first $6 \mathrm{~h}$ after the insult and then intermittently throughout (8).

$\mathrm{N}_{2} \mathrm{O}$ was turned off $30 \mathrm{~min}$ before the insult, and anesthesia was maintained during the insult with $0.8 \%$ halothane, which is one minimum alveolar concentration (1 MAC) for newborn pigs at $39^{\circ} \mathrm{C}(17)$ and has a cardiodepressant effect. Hypoxia was induced by reducing $\mathrm{Fio}_{2}$ to $\sim 6 \%$. $\mathrm{FiO}_{2}$ was then adjusted to the maximal level that gave LA EEG $<7 \mu \mathrm{V}$ while at the same time avoiding severe hypotension (MABP $<30 \mathrm{~mm} \mathrm{Hg}$ ) and bradycardia [heart rate $(\mathrm{HR})<100$ beats $/ \mathrm{min}$ ]. Severe bradycardia not responding to a transient increase in $\mathrm{Fio}_{2}$ was treated with chest compression in one NT and two HT animals for 1-3 min. Hypoxia was maintained for $45 \mathrm{~min}$ followed by reoxygenation. The $\mathrm{Fio}_{2}$ was adjusted to give $\mathrm{TcSaO}_{2} 95$ to $98 \%$. Anesthesia was stopped on reoxygenation. This is a change from previous studies with this model in which anesthesia was maintained for the first $6 \mathrm{~h}$ after the insult, i.e. during the period of reoxygenation followed by HT or NT (6, $18,19)$.

One-third correction of the base deficit by i.v. buffer [trometamol:tris(hydroxymethyl)aminomethane (THAM)], body weight $(\mathrm{kg}) \times$ base deficit $(\mathrm{mmol} / \mathrm{L}) \times 0.2$, was given if the apH was less than 7.0 (in $10 \mathrm{HT}$ and $11 \mathrm{NT}$ ). There was no relationship between any outcome measures and whether the piglet received THAM or not.

Mechanical ventilation was maintained as clinically required. HT and NT piglets were extubated after a median of 1.5 and $2.0 \mathrm{~h}$, respectively. After $6 \mathrm{~h}$, all HT and $13 \mathrm{NT}$ piglets were extubated. Ampicillin and gentamicin were given twice daily, and no animals had signs of infection. Fluid (5\% dextrose in $0.45 \% \mathrm{NaCl}$ ) was administered at $10 \mathrm{~mL} \cdot \mathrm{kg}^{-1} \cdot \mathrm{h}^{-1}$ i.v. during preparation followed by $5 \mathrm{~mL} \cdot \mathrm{kg}^{-1} \cdot \mathrm{h}^{-1}$ during the insult and for the first $24 \mathrm{~h}$, after which artificial milk by bottle was introduced as tolerated. Serum glucose and electrolytes were checked and supplemented if needed. Target range for glucose was $2.6-10 \mathrm{mmol} / \mathrm{L}$. MABP after the insult was maintained $\geq 40 \mathrm{~mm} \mathrm{Hg}$. Only one animal (HT) received dopamine, 10 $\mu \mathrm{g} \cdot \mathrm{kg}^{-1} \cdot \mathrm{min}^{-1}$, for $45 \mathrm{~min}$ during rewarming after HT. Bolus doses of $10 \%$ human albumin (median $10 \mathrm{~mL} / \mathrm{kg}$, range 7.5-20 $\mathrm{mL}$ ) were given to 12 animals (seven NT and five HT) during preparation to treat hypotension after induction of anesthesia.

HT to a target $\mathrm{T}_{\text {rectal }}$ of $35^{\circ} \mathrm{C}$ was achieved within 20 min by removing external heating and placing rubber gloves filled with cold water $\left(4-10^{\circ} \mathrm{C}\right)$ under and against the piglet's neck and body and was maintained by reducing incubator temperature to approximately $18^{\circ} \mathrm{C}$ and placing cold gloves as needed. After $24 \mathrm{~h}$ of $\mathrm{HT}$, animals were rewarmed to $39^{\circ} \mathrm{C}$ over $6 \mathrm{~h}$.

Blood gases were measured with a Radiometer ABL 4 blood gas analyzer adjusted for actual $\mathrm{Hb}$ value, and blood gas values 
were corrected for body temperature. Glucose was analyzed with a standard hexokinase method, and cortisol was measured using the RIA procedure Coat-A-Count (Diagnostic Products Corp., Los Angeles, CA, U.S.A.).

Seizure detection. Electroconvulsive activity was defined as rhythmic high-voltage spike/wave activity at a frequency of less than $2 \mathrm{~Hz}$ lasting more than $20 \mathrm{~s}$ and with spike height more than twice the background voltage. It was detected by continuous observation of the two-channel EEG trace at 1 or 25 $\mathrm{mm} / \mathrm{s}$ and later confirmed by examination of the paper trace or cassette recording by an investigator blinded to the temperature allocation of the pig. The onset of seizures was recorded and the proportion of time with seizures calculated for each 24-h period (Table 1). With recurrent seizures, the periods between seizures were included in the seizure time if they were shorter than the seizure periods.

The diagnosis of clinical seizures was made by observing clonic or tonic movements in a pig with simultaneous electrical seizure activity. If there was doubt about clonic/tonic movements, video film of the episode was reviewed by another investigator blinded to the temperature allocation. No anticonvulsant treatment was given.

Histopathology. At $72 \mathrm{~h}$ postinsult, the piglets were deeply halothane anesthetized and the brain perfusion fixed through the common carotid arteries with $4 \%$ phosphate-buffered paraformaldehyde. Three animals died prematurely due to cardiovascular consequences of the $\mathrm{HI}$ insult (one NT at $48 \mathrm{~h}$ and two HT at 33 and $46 \mathrm{~h}$ ); their brains were also perfusion fixed. All three were seizing $>50 \%$ of the time. Previously we have seen that animals that die prematurely after major insults and sur- vive at least 24-h have developed maximal histologic damage $(6,8)$.

Typical lesions in this model are cortical necrosis in the bottom of the sulci (ulegyria), white matter lesions, cerebellar infarcts, selective Purkinje cell necrosis, and hippocampal lesions (8). Five areas of the brain were examined (hippocampus, cortex/white matter, cerebellum, basal ganglia, and thalamus) by a pathologist (E.M.L.) blinded to the treatment intervention and any clinical data. The severity of damage in 15 cross-sections per brain (frontal to rostral) was graded on a 9 -step scale from 0.0 to 4.0 as previously described (8). All subjects had damage in at least one brain region.

Sham control animals. Three animals were fully instrumented and followed the same protocol as those randomized to 24-h HT followed by 48-h NT except that they did not undergo 45 min of hypoxia and were instead ventilated with room air.

Statistics. The SD for the mean pathology score without HT was known a priori as 0.95 (8) and was used to estimate a sample size of 15 to detect a difference of 1.0 in the pathology score with a power of $80 \%$ and a 2 -sided $p$ value of 0.05 . We started with a total of 44 animals to allow for pilot experiments; $n=2$, sham controls; $n=3$ and experimental problems; $n=$ 3 (see "Methods"). The piglets were randomized at the end of the insult by consecutively numbered sealed opaque envelopes in blocks of eight. Blocks were stratified according to whether the apH was above or below 7.0 at the end of hypoxia. Eighteen animals in each group were available for final analysis including the three that died prematurely. Mann-Whitney $U$ test, $t$ test, and simple regression were used as appropriate.

Table 1. Subject and insult information and blood chemistry and hematology results throughout the experimental period. Values are mean (SD) or median with range as indicated

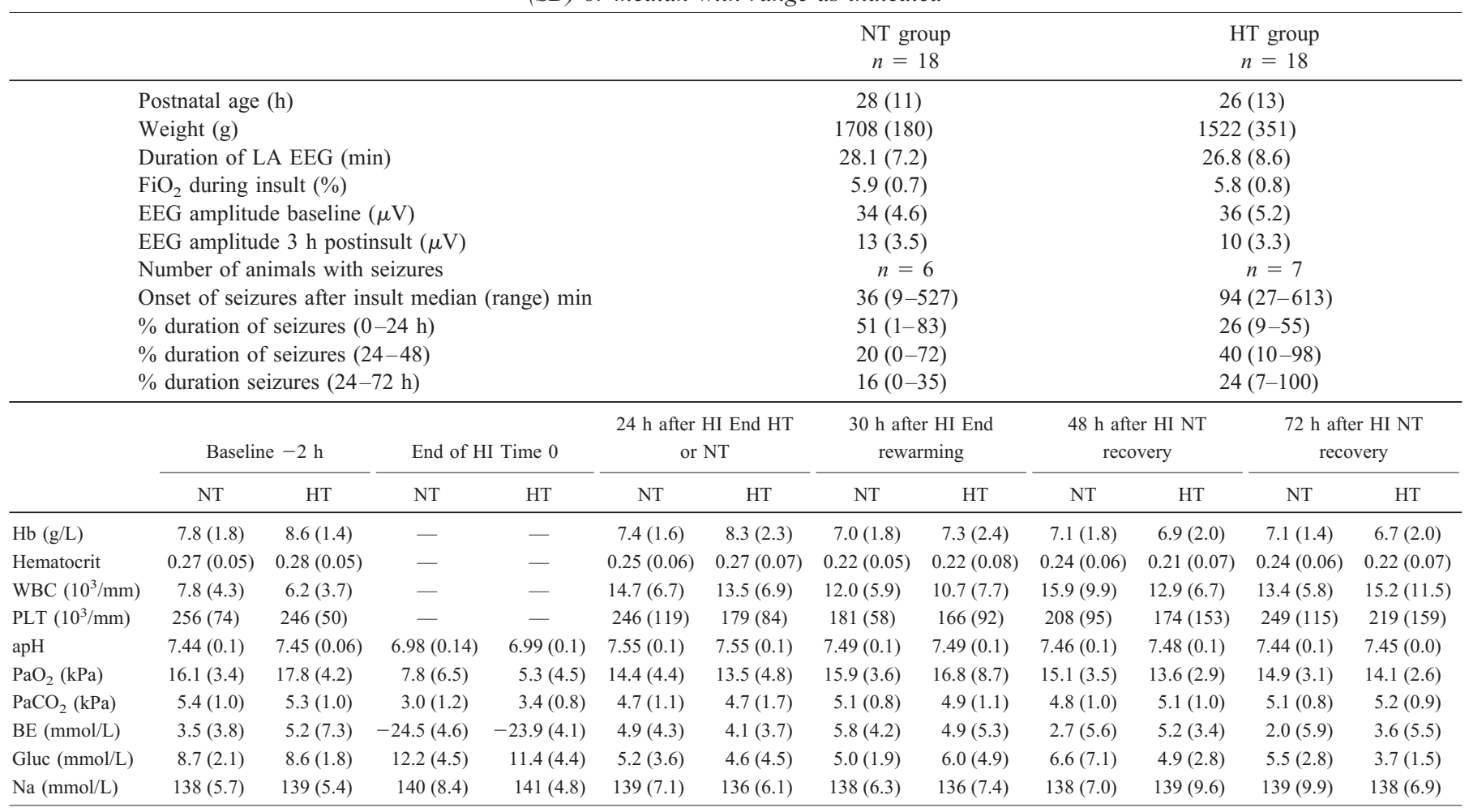


Results are given as mean $\pm \mathrm{SD}$ or median with interquartile range or total range as appropriate.

\section{RESULTS}

Neuropathologic damage and temperature allocation. There were no differences in the neuropathology score or the distribution of the brain damage between the HT and NT groups (Fig. 1). Thalamus was significantly less damaged than the other regions of the brain $(p=0.01)$ as seen in this model (8). All animals were damaged in at least one region. In Figure 2 , the relationship between individual pathology values in cortex/white matter and the duration of LA EEG during the 45 -min insult is displayed $\left(r^{2}=0.54, p=0.001\right)$.

The duration of LA EEG $(<7 \mu \mathrm{V})$ during the insult (mean HT $26.8 \pm 8.6$ versus NT $28.1 \pm 7.2 \mathrm{~min}$ ) was similar, as was the mean $\mathrm{FiO}_{2}$ between the two groups (HT $5.8 \pm 0.7$ versus NT $5.9 \pm 0.8$ ) (Table 1).

Seizure activity and temperature allocation. Seven HT and six NT pigs developed posthypoxic seizures. The median total duration of time with seizures during the $3 \mathrm{~d}$ was similar in the HT (30\%) and NT (29\%) groups. The seizure activity tended to occur earlier in the NT group with median time until onset 36 versus $94 \min (p=0.06)$ (Table 1$)$.

Neuropathologic damage and seizures. All regions of the brain were significantly more damaged in the group that developed seizures than in the group that did not. There was no significant difference between those that seized in the HT and NT groups.

In the piglets that seized, the median and total range pathology scores for hippocampus, cortex/white matter, cerebellum, basal ganglia, and thalamus were $4(3.5-4.0), 4(3.5-4.0), 3$ $(1.75-3.5), 3(3-3.5)$, and $1.5(1.0-2.5)$, respectively, in the HT group and $3.5(3-3.5), 3.0(3.0-3.5), 2.5$ (1.5-3), 2.5 $(2.5-3.0)$, and $1.0(0-1.5)$ in the NT group. The HT animals that seized tended to be more damaged $(p=0.06)$. There was also a significant association between early onset of seizures and the severity of damage $\left(r^{2}=0.21, p=0.003\right)$. In the piglets that did not seize, the pathology scores (median and

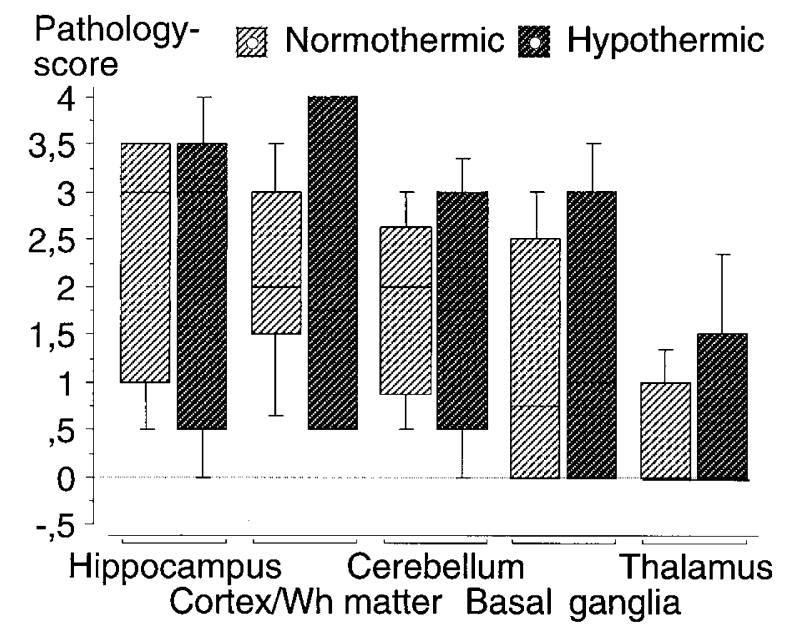

Figure 1. Shows the median pathology scores (and interquartile range) for the different areas of the brain in the HT group $\left(24 \mathrm{~h}\right.$ of $35^{\circ} \mathrm{C} \mathrm{T}_{\text {rectal }}$ followed by $48 \mathrm{~h}$ of $\mathrm{NT}, 39^{\circ} \mathrm{C}$ ) and NT group $\left(\mathrm{T}_{\text {rectal }} 39^{\circ} \mathrm{C}\right.$ for $\left.72 \mathrm{~h}\right)$.

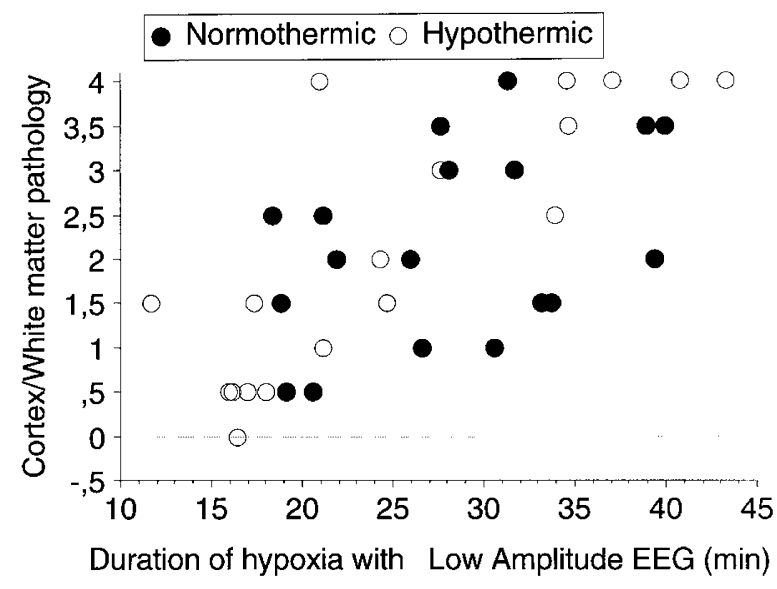

Figure 2. Shows the relationship between a 9-step pathology score (from 0.0 to 4.0) in cortex/white matter and the duration in minutes of the total hypoxic insult (45 min); the EEG amplitude was lower than $7 \mu \mathrm{V}$.

total range) for hippocampus, cortex/white matter, cerebellum, basal ganglia, and thalamus were $0.5(0.0-3.5), 1.0(0-3.0)$, $1.0(0.0-3.0), 0.0(0.0-2.5)$, and $0.0(0.0-1.0)$, respectively, in the HT group and $2.25(0.0-3.5), 1.5(0.5-2.5), 1.5(0.5-3.0)$, $0.0(0.0-2.0)$, and $0.0(0.0-1.0)$ in the NT group. These results were not significantly different between HT and NT.

Two physiologic factors during the insult were the main predictors of later occurrence of seizures. The duration (median, range) of LA EEG during the 45-min insult was 34.5 (30.5-39) $\mathrm{min}$ in the group that developed seizures versus 21 (17.5-26.5) $\mathrm{min}$ in the group with no seizures $(p<0.001)$. The MABP during the insult was lower in the animals that went on to seize, in particular during the last $15 \mathrm{~min}$ of the insult, 38 (34.5-42.5) versus $50(41-55) \mathrm{mm} \mathrm{Hg}$ in the group without seizures $(p=0.005)$. For the first $0-12 \mathrm{~h}$ after the insult, $\mathrm{MABP}$, apH, or glucose was not related to the occurrence of seizures.

Hypothermic sham control animals. The brains were all normal with no damage in any region. The EEG at baseline, 3, and $72 \mathrm{~h}$ had normal background activity of $30-40 \mu \mathrm{V}$. The cardiovascular and biochemical parameters were also normal throughout with the following median values at baseline, after 24, 48, and $72 \mathrm{~h}$, respectively: $\mathrm{T}_{\text {rectal }}{ }^{\circ} \mathrm{C}, 39.0,34.5,39.0,39.1$; HR beats/min, 145 (anesthetized at baseline), 181, 190, 175; $\mathrm{Hb}$ g/100 mL, 6.7, 7.1, 7.5, 6.0; pH, 7.42, 7.40, 7.41, 7.42; $\mathrm{P}_{\text {venous }} \mathrm{CO}_{2} \mathrm{kPa}, 50.1,49.5,51.3,49.0$; base excess (BE) $\mathrm{mmol} / \mathrm{L}, 7.8,6.2,8.5,1.1$; glucose $\mathrm{mmol} / \mathrm{L}, 8.0,6.5,6.0,6.0$.

Physiologic and biochemical data and temperature allocation. Table 1 shows that the two groups of pigs had similar physiologic and biochemical values before, at the end of the 45-min HI insult, and after 24, 48, or $72 \mathrm{~h}$ for $\mathrm{Hb}$, hematocrit, white blood cell count, platelets, glucose, sodium, and arterial blood gas values. We analyzed specifically those factors during the insult thought to be associated with neurologic damage: temperature, $\mathrm{HR}$, blood pressure, $\mathrm{Fio}_{2}, \mathrm{apH}, \mathrm{PaCO}_{2}, \mathrm{PaO}_{2}$, and glucose. There was no difference between the NT and HT groups in any parameter we recorded during the insult (Table 1 and Fig. 3). After the insult, $\mathrm{T}_{\text {rectal }}$ was reduced by $4^{\circ}$ in the 
HT group for $24 \mathrm{~h}$ according to protocol. MABP or HR was similar in the HT and NT groups (Fig. 3).

Cortisol. In the HT group, plasma cortisol rose during the 24-h HT period to values 3 times the NT values (Fig. 4) and was significantly higher. After rewarming for $6 \mathrm{~h}$, the HT values had normalized and were not different from the NT values. The decline in cortisol seen in the NT animals is normal for pigs from d 1 to 3 (20).
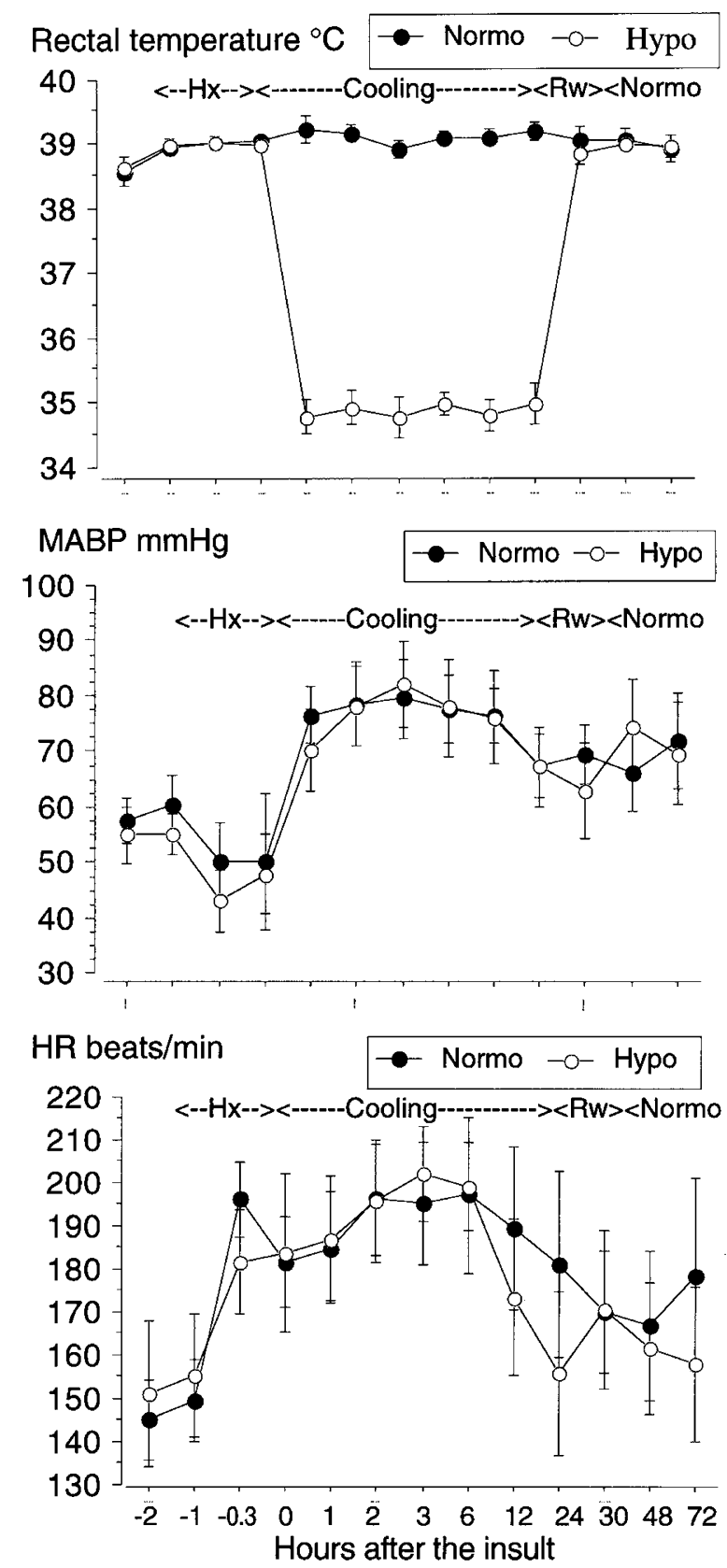

Figure 3. Upper panel shows the mean $( \pm \mathrm{SD}) \mathrm{T}_{\text {rectal }}$ in the NT and HT groups throughout the whole experimental period. Only during induced HT is there a difference in temperature. Middle panel shows the MABP in the NT and HT groups. There is never a difference in blood pressure between the groups. The animals were anesthetized during preparation and baseline recordings $(-2$ h) until time 0 (end of insult), after which inhalation anesthesia was stopped. Lower panel shows there is no difference in HR between the two groups, although there is a trend for HR in the HT group to drop during the last $12 \mathrm{~h}$ of HT. $R w$ indicates rewarming.

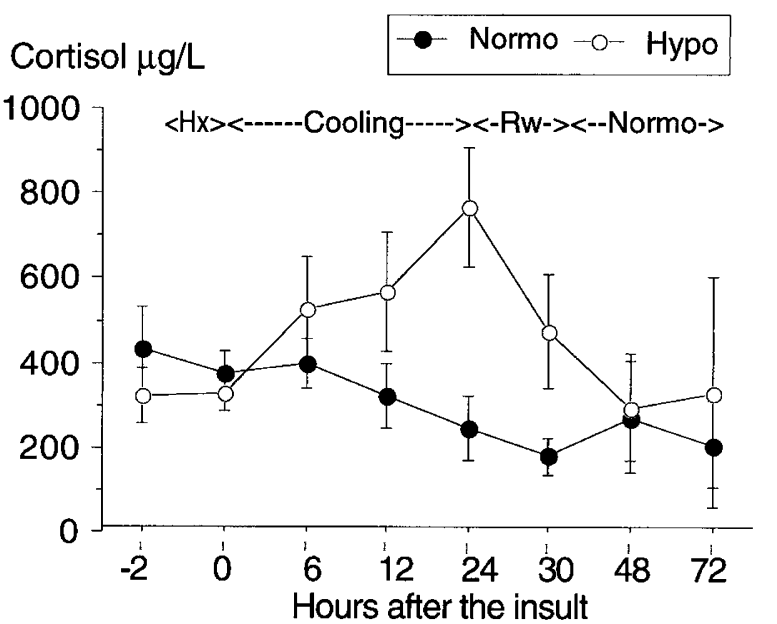

Figure 4. Plasma cortisol levels in the HT $(n=18)$ and NT $(n=18)$ groups of animals. Rw takes place from 24 to $30 \mathrm{~h}$ after the insult.

\section{DISCUSSION}

We found no neuroprotective effect of 24-h posthypoxic HT based on neuropathology or a reduction in the number of animals that developed seizures. This finding is in contrast with previous studies (21) that demonstrate neuroprotection in the newborn pig $(1,6)$, lamb (4), and rat $(2,3,7)$ by use of posthypoxic HT lasting from 3 to $76 \mathrm{~h}$. No study in newborn animals has compared the effect of different durations of HT. Moderate neuroprotection was found at 3-d survival after $3 \mathrm{~h}$ of $4^{\circ}$ reduction (6). Twelve hours of $4^{\circ}$ HT showed better protection in another piglet study (1). In both studies, the animals were fully anesthetized during HT. Based on these findings, we choose $24 \mathrm{~h}$ as a duration likely to be effective. The choice of a $4^{\circ}$ temperature reduction was based on data from adult rats (22) and our pilot temperature study (16) as well as knowledge of possible adverse effects with moderate hypothermia (23).

Although one might suggest that the failure of neuroprotection could be connected to the absence of vessel occlusion in our model, we find that an unlikely explanation because our model does achieve a significant degree of ischemia secondary to hypoxic cardiodepression. We have found partial neuroprotection in our model with only $3 \mathrm{~h}$ of HT under anesthesia. Also, in a cerebral microdialysis study, we found a reduction in excitatory amino acids and citrulline/arginine ratio in the HT compared with the NT animals (18). HI brain injury in human newborns is not due to large vessel occlusion, and our model produces widespread brain injury with an anatomical distribution similar to that found in the full-term infant.

We speculate that the lack of protection in this study may be due to the stress of being cooled while awake, as previous studies on piglets that achieved protection were all performed on anesthetized animals.

The current study is, to our knowledge, the only experimental study in which the newborn pigs have not been anesthetized during posthypoxic HT.

We chose not to anesthetize the animals postinsult, as anesthesia is not routine practice with newborns after HI. Infants are usually sedated on clinical indication, e.g. if they are unsettled while being ventilated. The anesthetic could mask the 
occurrence of seizures. We have not treated clinical seizures because treatment is relatively ineffective in humans (24) as well as in our model $(6,8)$. This group of drugs may be neuroprotective in themselves (25), and the administration may not be evenly distributed between the groups. Therefore, we followed the natural course of HI encephalopathy only supporting homeostasis.

Unsedated and conscious subjects that are cooled will try to maintain NT by increasing their metabolism by use of age- and species-specific strategies. Newborns with brown fat like the rat, rabbit, and man do not shiver but will turn on nonshivering thermogenesis $(26,27)$. Newborn species without brown fat like the pig will shiver $(12,13)$ and increase their metabolism by up to $300 \%$. In awake adult humans, shivering increased whole body oxygen consumption by $110 \%$ when body temperature was reduced by $1.3^{\circ} \mathrm{C}(28)$, and shivering increased cerebral metabolism by $100 \%$ at HT temperatures in a small study on humans (29). The metabolic and temperature response to cooling if the subject is hypoxic is, however, different in newborns. In rabbits, mice, and rats, the temperaturepreserving mechanisms are actively turned off and the animal becomes colder $(26,30,31)$, which is seen to be a normal protective response by the hypoxic newborn. Burnard and Cross (32) measured $\mathrm{T}_{\text {rectal }}$ for $24 \mathrm{~h}$ after birth on vaginally delivered infants who were either normal at birth or moderately asphyxiated. Thirty minutes after delivery, the asphyxiated infants were $2{ }^{\circ} \mathrm{C}$ colder than the healthy infants despite similar thermal care, and, after $20 \mathrm{~h}$, their temperature was only $35.5^{\circ} \mathrm{C}$.

In a fetal lamb HI model, cooling was provided by a coil of circulating cold water around the fetus. The fetus does not have any temperature regulatory responses itself and will not try to increase its heat production by shivering. We have, therefore, no measure of stress during intrauterine cooling in this model in which posthypoxic cooling for $72 \mathrm{~h}$ has shown excellent neuroprotection (4).

HT after unilateral carotid ligation and hypoxia in the unsedated 7- or 14-d-old rat has shown good neuroprotection (2, 3, 5). Newborn rats do not shiver but increase their metabolism by burning brown fat during HT. They do not increase their motor activity while cold after hypoxia but huddle together quietly and have a drop in HR corresponding to the HT (33). In adult brain trauma studies, the patients are always paralyzed and anesthetized during HT $(9,10,34)$; hence, we have no comparative human data on HT without sedation.

Recent human pilot studies examined the efficacy and safety of total body cooling or selective head cooling during neonatal encephalopathy in infants who were not routinely sedated (35-38).

\section{Stress, HT, and Neuroprotection}

There is mounting evidence that stressful experiences exacerbate disease processes. Physiologic responses to stress include hypertension, tachycardia, and activation of the hypothalamic-pituitary-adrenal axis and release of cortisol. The brain, particularly the hippocampus, is a principal target organ for circulating glucocorticoids. The hippocampus is vulnerable to degenerative effects of stress (39). Swim stress, chronic han- dling stress, and limb restraint increase cortisol levels and hippocampal damage (40-42). Carlsson et al. (41) reported doubling of cerebral oxygen consumption in unanesthetized restrained rats.

In the same study, they blocked the adrenal response to stress by spinal anesthesia and eliminated the cerebral metabolic effects of restraint stress.

It is suggested that corticosteroids released during stress cause energy depletion in the brain, making it more vulnerable to exitotoxicity (43).

What evidence do we have that the cooled piglets were more stressed than the NT piglets? The main evidence is the steady increase in cortisol levels during HT, which fell immediately to normal levels on rewarming. Cortisol in piglets is a good marker of stress $(44,45)$. The lack of the expected reduction in HR during HT is an indirect marker of increased metabolic stress. In our previous studies of anesthetized piglets, the HR dropped by an average of 50 from 190 to 140 beats/min during mild HT $(6,16-18)$. In our clinical pilot study of posthypoxic cooling, nearly all the infants were sedated, and the HR was reduced from 145 to 100 beats/min during $72 \mathrm{~h}$ of cooling. The present study of unsedated piglets never showed a reduction in HR during HT.

In a study in which newborn piglets were kept in a cold $\left(22^{\circ} \mathrm{C}\right)$ or warm $\left(33^{\circ} \mathrm{C}\right)$ environment, the cold piglets were standing or moving $40 \%$ of the time compared with $8 \%$ in those who were kept warm. Those kept cold had higher plasma cortisol levels (46). In our study, the HT piglets were awake, more unsettled, and shivered more of the time than those that were NT.

\section{Seizures}

There are conflicting results as to whether HT reduces seizures per se. Anecdotally, maternal HT has been reported to stop eclamptic seizures and improve outcome in the infant (47). Also, HT has been reported to successfully treat status epilepticus (48). Reduced neuronal excitability was found when hippocampal slices were cooled $(49,50)$. In a trial of adults body-cooled to $33.5^{\circ} \mathrm{C}$ after brain trauma, the same numbers of patients were reported to seize in both the HT and NT groups (9). Also, in a trial of HT after out-of-hospital cardiac arrest, the same proportion seized in each group (51). In a fetal lamb cerebral HI model, $72 \mathrm{~h}$ of HT was not found to reduce the occurrence of seizures $(4,52)$. In our previous studies with short-lasting HT, the same proportion of animals seized in each group $(6,18,19)$. In the current study in which no anticonvulsants were given and anesthesia was stopped immediately after the insult, there was a trend toward earlier onset of seizures in the NT than the HT animals. However, the HT group stopped seizing later; hence, the total time the two groups seized was the same (Table 1).

In conclusion, $24 \mathrm{~h}$ of mild HT without sedation failed to reduce neuropathologic damage or seizure activity in our newborn model of global hypoxia. This finding may be due to increased stress during HT. Multicenter trials of mild HT as therapy for newborn infants with neonatal encephalopathy have started, and routine sedation is not a part of the protocol. 
If our findings apply to humans as well as pigs, we speculate that inadequate sedation of infants undergoing HT as therapy may block the protective effects of HT on the posthypoxic brain. We suggest that clinical and experimental research on the appropriateness of sedation during HT is urgent.

Acknowledgments. The authors thank Fabio Apricena and Martin Runde for expert technical assistance, and Dr. Petter Urnes at the Clinical Laboratory at Ullevål Hospital for performing the biochemistry analysis.

\section{REFERENCES}

1. Thoresen M, Penrice J, Lorek A, Wyatt J, Cady EB, Wylezinska M, Kirkbridge V, Cooper C, Edwards D, Brown G, Reynolds EOR 1995 Mild hypothermia after severe transient hypoxia-ischemia ameliorates delayed cerebral energy failure in the newborn piglet. Pediatr Res 5:667-670

2. Thoresen M, Bågenholm R, Løberg EM, Apricena F, Kjellmer I 1996 Posthypoxic cooling of neonatal rats provides protection against brain injury. Arch Dis Child 74:F3-F9

3. Sirimanne ES, Blumberg RM, Bossano D, Gunnong M, Edwards AD, Gluckman PD, Williams CE 1996 The effect of prolonged modification of cerebral temperature on the outcome after hypoxic-ischemic brain injury in the infant rat. Pediatr Res 39:591-597

4. Gunn AJ, Gunn TR, deHaan HH, Williams CE, Gluckman PD 1997 Dramatic neuronal rescue with prolonged selective head cooling after ischemia in fetal sheep. J Clin Invest 99:248-256

5. Bona E, Løberg EM, Bågenholm R, Hagberg H, Thoresen M 1998 Protective effects of moderate hypothermia after neonatal hypoxia-ischemia: short and long-term outcome. Pediatr Res 43:738-745

6. Haaland K, Løberg EM, Steen PA, Thoresen M 1997 Posthypoxic hypothermia in newborn piglets. Pediatr Res 41:505-512

7. Trescher WH, Ishiwa S, Johnston MV 1997 Brief post-hypoxic-ischemic hypothermia markedly delays neonatal brain injury. Brain Dev 19:326-338

8. Thoresen M, Haaland K, Løberg EM, Apricena F, Hankø E, Whitelaw A, Steen PA 1996 A piglet survival model for posthypoxic encephalopathy. Pediatr Res 40:738748

9. Marion DW, Penrod LE, Kelsey ST, Obrist WD, Kochanek PM, Palmer AM, Wisniewski SR, DeKosty ST 1997 Treatment of traumatic brain injury with moderate hypothermia. N Eng J Med 336:540-546

10. Metz C, Holzschuh M, Bein T, Woertgen C, Frey A, Frey I, Taeger K, Brawanski A 1996 Moderate hypothermia in patients with severe head injury: cerebral and extracerebral effects. J Neurosurg 85:533-541

11. Levene MI 1993 Management of the asphyxiated full-term infant. Arch Dis Child 68:612-616

12. Kurz M, Belani KG, Sessler DI, Kurz A, Larson MD, Schroeder M, Blanchard D 1993 Naloxone, meperidine, and shivering. Anesthesiology 79:1193-1201

13. Berthon D, Herpin P, Ledividich J 1994 Shivering thermogenesis in the neonatal pig. J Therm Biol 19:413-418

14. Lossec G, Herpin P, Dividich JL 1998 Thermoregulatory responses of the newborn pig during experimentally induced hypothermia and rewarming. Exp Physiol 83:667678

15. Mount LE, Rowell JG 1960 Body size, body temperature, and age in relation to the metabolic rate of the pig in the first five weeks after birth. J Physiol 154:408-416

16. Haaland K, Steen PA, Thoresen M 1996 Cerebral, tympanic, and colonic thermometry in the piglet. Reprod Fert Develop 8:125-128

17. Satas S, Haaland K, Thoresen M, Steen PA 1996 MAC for halothane and isoflurane during normothermia and hypothermia in the newborn piglet. Acta Anaesthesiol Scand 40:452-456

18. Thoresen M, Satas S, Puka-Sundvall M, Whitelaw A, Hallström Å, Løberg EM, Ungerstedt U, Steen PA, Hagberg H 1997 Posthypoxic hypothermia reduces cerebrocortical release of NO and excitotoxins. Neuroreport 8:3359-3362

19. Thoresen M, Hallstrøm Å, Puka-Sundvall M, Løberg EM, Satas S, Steen PA, Ungerstedt U, Whitelaw A, Hagberg H 1998 Lactate and pyruvate changes in the brain gray and white matter during posthypoxic seizures in newborn pigs. Pediatr Res 44:746-755

20. Kattesh HG, Charles SF, Baumbach GA, Gillespie BE 1990 Plasma cortisol distribution in the pig from birth to six weeks of age. Biol Neonate 58:220-226

21. Thoresen M 2000 Cooling the newborn after asphyxia - physiological and experimental background and its clinical use. Semin Neonatol 5:61-73
22. Carroll M, Beek O 1992 Protection against hippocampal CA1 cell loss by postischemic hypothermia is dependent on delay of initiation and duration. Met Brain Dis 7:45-50

23. Schubert A 1995 Side effects of mild hypothermia. J Neurosurg Anesthesiol 7:139147

24. Painter MJ, Scher MS, Stein AD, Armatti S, Wang Z, Gardiner JC, Paneth N, Minnigh B, Alvin J 1999 Phenobarbital compared with phenytoin for the treatment of neonatal seizures. N Engl J Med 341:485-489

25. Hall RT, Hall FK, Daily DK 1998 High-dose phenobarbital therapy in term newborn infants with severe perinatal asphyxia: a randomized prospective study with threeyear follow up. J Pediatr 132:345-348

26. Dawkins MJR, Hull D 1964 Brown adipose tissue and the response of new-born rabbits to cold. J Physiol 172:216-238

27. Aherne W, Hull D 1966 Brown adipose tissue and heat production in the newborn infant. J Pathol Bact 91:223-234

28. Frank SM, Higgins MS, Fleisher LA, Sitzman JV, Raff H, Breslow MJ 1997 Adrenergic, respiratory, and cardiovascular effects of core cooling in humans. Am J Physiol 272:R557-R562

29. Stone BH, Donelly C, Frobese AS 1956 The effect of lowered body temperature on the cerebral hemodynamics and metabolism of man. Surg Gynecol Obstet 313-317

30. Blatteis CM 1964 Hypoxia and the metabolic response to cold in newborn rabbits. J Physiol 172:358-368

31. Gordon C, Fogelson L 1991 Comparative effects of hypoxia on behavioral thermoregulation in rats, hamsters, and mice. Am J Physiol 260:R120-R125

32. Burnard ED, Cross KW 1958 Rectal temperature in the newborn after birth asphyxia. BMJ 1197-1199

33. Adolph EF 1951 Responses to hypothermia in several species of infant mammals Am J Physiol 166:75-87

34. Clifton GL, Allen S, Barrodale P, Plenger P, Berry J, Koch S, Fletcher J, Hayes RL, Choi SC 1993 A phase II study of moderate hypothermia in severe brain injury. J Neurotrauma 10:263-271

35. Gunn AJ, Gluckman PD, Gunn TR 1998 Selective head cooling in newborn infants after perinatal asphyxia: a safety study. Pediatrics 102:885-892

36. Simbruner G, Haberl C, Harrison V, Linley L, Willeitner AE 1999 Induced brain hypothermia in asphyxiated newborn infants: a retrospective chart analysis of physiological and adverse effects. Intensive Care Med 25:1111-1117

37. Thoresen M, Whitelaw A 2000 Cardiovascular changes during mild therapeutic hypothermia and rewarming in infants with hypoxic-ischemic encephalopathy. Pediatrics 106:103-111

38. Azzopardi D, Robertson NJ, Cowan FM, Rutherford MA, Rampling M, Edwards AD 2000 Pilot study of treatment with whole body hypothermia for neonatal encephalopathy. Pediatrics 106:684-694

39. McEwen BS, Albeck DA, Cameron H, Chao HM, Gould E, Hastings N, Kuruda Y, Luine V, Magarinos AM, McKittrick CR, Orchinik M 1995 Stress and the brain: a paradoxical role for adrenal steroids. Vitam Horm 51:371-402

40. Ishizuka N, Weber J, Amaral DG 1990 Organization of the intrahippocampal projections originating from CA3 pyramidal cells in the rat. J Comp Neurol 295:580 623

41. Carlsson C, Hägerdal M, Kaasik AE, Siesjö BK 1977 A cathecholamine mediated increase in cerebral oxygen uptake during immobilization stress in rats. Brain Res 119:223-233

42. Smith MA 1996 Hippocampal vulnerability to stress and aging: possible role of neurothropic factors. Behav Brain Res 78:25-36

43. Luine V, Villegas M, Martinez C, McEwen BS 1994 Repeated stress causes reversible impairments of spatial memory performance. Brain Res 639:167-170

44. Becker BA, Nienaber JA, Christenson RK, Manak RC, DeShazer JA, Hahn GL 1985 Peripheral concentrations of cortisol as an indicator of stress in the pig. Am J Vet Res 46:1034-1040

45. Rampacek GB, Kraeling RR, Fonda ES 1984 Comparison of physiological indicators of chronic stress in confined and nonconfined gilts. J Anim Sci 58:401-408

46. Hicks TA, McGlone JJ, Whisnant CS, Kattesh HG, Norman RL 1998 Behavioral, endocrine, immune, and performance measures for pigs exposed to acute stress. J Anim Sci 76:474-483

47. Barter RH, Albert SN, Winshel AW 1958 The use of hypothermic-hypotensive technique in fulminant toxemia of pregnancy. Am J Obstet Gynecol 76:1062-1070

48. Aminoff MJ 1998 Management of status epilepticus. Can J Neurol Sci 25:S4-S6

49. Hiramatsu K, Kassell NF, Lee KS 1993 Thermal sensitivity of hypoxic responses in neocortical brain slices. J Cereb Blood Flow Metab 13:395-401

50. Morris ME, LeBlond J, Agopyan N, Krnjevic K 1991 Temperature dependence of extracellular ionic changes evoked by anoxia in hippocampal slices. J Neurophysiol 65:157-167

51. Bernard SA, MacJones B, Horne KM 1997 Clinical trial of induced hypothermia in comatose survivors of out-of-hospital cardiac arrest. Ann Emerg Med 30:146-152

52. Gunn AJ, Gunn TR, Gunning MI, Williams CE, Gluckman PD 1998 Neuroprotection with prolonged head cooling started before postischemic seizures in fetal sheep. Pediatrics 102:1098-1106 